University of Nebraska - Lincoln

DigitalCommons@University of Nebraska - Lincoln

Sociology Department, Faculty Publications

Sociology, Department of

$11-2000$

\title{
Predictors of Self-reported Sexually Transmitted Diseases among Homeless and Runaway Adolescents
}

\author{
Kimberly A. Tyler \\ University of Nebraska-Lincoln, kim@ktresearch.net \\ Les B. Whitbeck \\ University of Nebraska-Lincoln, Iwhitbeck2@unl.edu \\ Dan R. Hoyt \\ University of Nebraska-Lincoln, dhoyt2@unl.edu \\ Kevin A. Yoder \\ lowa State University
}

Follow this and additional works at: https://digitalcommons.unl.edu/sociologyfacpub

Part of the Sociology Commons

Tyler, Kimberly A.; Whitbeck, Les B.; Hoyt, Dan R.; and Yoder, Kevin A., "Predictors of Self-reported Sexually Transmitted Diseases among Homeless and Runaway Adolescents" (2000). Sociology Department, Faculty Publications. 60.

https://digitalcommons.unl.edu/sociologyfacpub/60

This Article is brought to you for free and open access by the Sociology, Department of at DigitalCommons@University of Nebraska - Lincoln. It has been accepted for inclusion in Sociology Department, Faculty Publications by an authorized administrator of DigitalCommons@University of Nebraska - Lincoln. 


\title{
Predictors of Self-reported Sexually Transmitted Diseases among Homeless and Runaway Adolescents
}

\author{
Kimberly A. Tyler, ${ }^{1}$ Les B. Whitbeck, ${ }^{2}$ Dan R. Hoyt ${ }^{2}$ and Kevin A. Yoder ${ }^{2}$ \\ ${ }^{1}$ University of Central Florida, Orlando, Florida, USA \\ ${ }^{2}$ Iowa State University, Ames, Iowa, USA
}

\begin{abstract}
Path analysis was used to investigate factors associated with self-reported sexually transmitted diseases among 569 homeless and runaway adolescents in four Midwestern states. Youth were interviewed by outreach workers directly on the streets, in shelters, and in drop-in centers. Results indicated that family abuse was positively related to substance use, affiliation with friends who sold sex, and time on own. Early family abuse indirectly increased the likelihood of self-reported sexually transmitted diseases through time on own, substance use, friends selling sex, and risky sexual behaviors. Finally, substance use and affiliation with friends who sold sex was positively associated with risky sexual behaviors, which in turn was related to self-reported sexually transmitted diseases. No significant gender interactions were found for this model.
\end{abstract}

$\mathrm{H}$ omeless and runaway adolescents are at risk for a variety of serious health problems, and length of time on the street is related to poor physical health (Farrow, Deisher, Brown, Kulig, \& Kipke, 1992; Unger et al., 1998). In addition, many of these young people engage in health-compromising behaviors such as substance use and survival sex (Johnson, Aschkenasy, Herbers, \& Gillenwater, 1996; Kipke, O'Connor, Palmer, \& MacKenzie, 1995; Yates, MacKenzie, Pennbridge, \& Cohen, 1988), which are likely to increase their risk for contracting sexually transmitted diseases (STDs). In fact, runaway adolescents have higher rates of intravenous drug use and prostitution than do nonrunaway adolescents (Yates et al., 1988). In general, teenagers are particularly vulnerable to contracting STDs because of high rates of unprotected sexual intercourse, experimentation with drugs, and early initiation of sexual intercourse (Cates, 1991; Sonenstein, Pleck, \& Ku, 1989). Initiating sexual intercourse at an early age puts teenagers at risk for longer time periods and increases their exposure to multiple sex partners.

Alarming rates of sexually transmitted diseases have been recorded among adolescents. Three million teenagers contract an STD each year, and approximately one quarter of sexually active adolescents become infected with an STD annually (Page, 1995). Since the majority of runaways report having engaged in sexual intercourse (Kipke et al., 1995; Rotheram-Borus et al., 1992), this is a cause for concern. These high rates call into question factors that are associated with contracting a sexually transmitted disease.

\section{Risk Amplification Model}

In the current study, we propose a set of hypotheses based on a risk amplification model to examine predictors of self-reported sexually transmitted diseases among homeless and runaway adolescents. The risk amplification model, which draws from life course developmental theory (Elder, 1997) and social interaction theory (Patterson, 1982), suggests that adolescents who leave dysfunctional and disorganized homes continue on negative developmental trajectories that lead to participation in healthcompromising behaviors (Whitbeck, Hoyt, \& Yoder, 1999), and this increases their risk for contracting STDs.

Patterson has argued that coercive families provide "basic training" for antisocial behaviors (Patterson, Dishion, \& Bank, 1984), which is the result of continuous failure on the part of the parents to use effective discipline techniques in controlling coercive exchanges between family members. Through this training, the child learns to control other family members by coercion, and these interaction styles are generalized into other contexts. These coercive and abusive behaviors become coping styles that are carried with the adolescent into peer interactions, which results in rejection by normal peer groups (Patterson, DeBaryshe, \& Ramsey, 1989; Patterson et al., 1984). As adolescents leave their dysfunctional/abusive families, interactions patterns learned at home are carried into early independence. The "basic training" for antisocial behavior in the family becomes "advanced training" on the streets (Whitbeck et al., 1999). 
In summary, adolescents who have experienced family abuse are likely to begin a negative developmental trajectory whereby they run away from home at early ages and spend more time on the street. Once on the street, the combination of antisocial behavior and rejection by conventional peers leads adolescents to form ties with deviant peer groups that are important for explaining adolescents subsequent involvement in risky, deviant behaviors (Whitbeck, Hoyt, \& Ackley, 1997a; Whitbeck et al., 1999). Their participation in such activities is likely to be associated with self-reported sexually transmitted diseases.

\section{Hypothesized Model}

The hypothesized model is presented in Figure 1. Research finds that many runaway adolescents come from abusive family backgrounds (Janus, McCormack, Burgess, \& Hartman, 1987; Whitbeck et al., 1997a). Furthermore, many of these young people often list physical and sexual abuse as important reasons for leaving home. For example, Whitbeck and Simons (1990) found that $24 \%$ of runaway adolescents listed sexual abuse as an important reason for leaving home, whereas $43 \%$ indicated physical abuse. In another study of homeless youth, $21 \%$ of respondents reported leaving home due to physical abuse and 7\% left home due to sexual abuse (Cauce et al., 1998). As indicated by Janus et al. (1987), “... these youth are running from something, not running to something" (p. 17). Studies have also found a connection between early abuse and running away numerous times and spending time on the street (Janus et al., 1987; Whitbeck \& Simons, 1990). Janus et al. (1987) noted that many runaways were from dysfunctional families with little social support available and often times will search for a better life. Whitbeck and Simons (1990) also found that homeless adolescents who had been abused were multiple runaways, and, therefore, likely to spend more time on their own. Following this, it was expected that a positive association would be found between family abuse and time on own (See Figure 1, Arrow A).

Adolescents who have experienced childhood abuse report high levels of substance use (Dembo et al., 1989; Garnefski \& Arends, 1998; Harrison, Fulkerson, \& Beebe,
1997). It is possible that the use of alcohol and drugs may deaden the pain that many of these adolescents experience as a result of the abuse. Furthermore, children from coercive and abusive families also have been found to be rejected by normal peer groups (Patterson et al., 1984), which results in their association with nonconventional peers (Whitbeck et al., 1997a). Therefore, it was hypothesized that family abuse would be positively related to substance use and affiliation with deviant peers who have traded sex (See Figure 1, Arrows B).

Being homeless and spending time on the street cultivates involvement in deviant subsistence strategies (Hagan \& McCarthy, 1997; Whitbeck \& Hoyt, 1999; Whitbeck \& Simons, 1990). Moreover, it has been found that the amount of time that youth spend on the street is positively related to both substance use (Whitbeck et al., 1999) and substance abuse (Kipke, Montgomery, Simon, \& Iverson, 1997). It is possible that substance use eases the pain that many of these young people experience as a result of being on the street (Farrow et al., 1992; Kipke, Montgomery, et al., 1997). Accordingly, it was hypothesized that time on own would be positively related to substance use (See Figure 1, Arrow C).

Studies have found that homeless youth form ties with other street youth who have similar behaviors and lifestyles (Kipke, Unger, O'Connor, Palmer, \& LaFrance, 1997). It is also possible that homeless youth are more reliant on their peers for support when lacking conventional family ties (Unger et al., 1998). Finally, Hagan and McCarthy (1997) found that runaways often form ties with other street youth for safety and protection. In general, spending more time on the street increases the opportunity for runaways to form ties with deviant peers (Whitbeck \& Hoyt, 1999). Following this, it was predicted that time on own would be positively associated with friends selling sex (See Figure 1, Arrow D).

Runaway and homeless youth who spend more time on their own report being offered money for sex (Janus et al., 1987). With few legitimate means of support, many runaways resort to survival sex or are sometimes coerced into the sex trade by pimps (Silbert \& Pines, 1981; Weisberg, 1985), thereby exposing them to numerous sexual part-

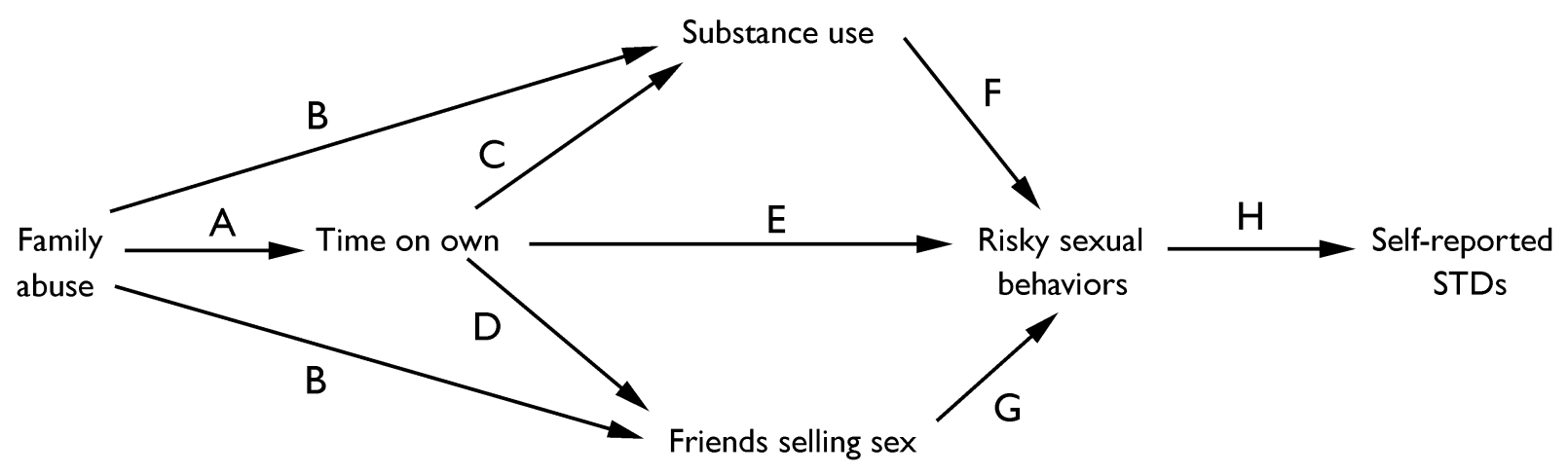

Figure 1. Hypothesized model for self-reported STDs among homeless and runaway adolescents. 
ners. In addition, studies also have found high rates of sexual activity among homeless youth but low rates of condom use (Anderson, Freese, \& Pennbridge, 1994; Johnson et al., 1996). It is possible that youth who spend more time on their own have fewer resources available (e.g., access to condoms), therefore reducing the likelihood of consistent condom use during sexual intercourse. Following this, it was expected that time on own would be positively associated with risky sexual behaviors (See Figure 1, Arrow E).

Substance use has been found to be associated with risky sexual behaviors (Fortenberry, Costa, Jessor, \& Donovan, 1997; Kipke et al., 1995; Koopman, Rosario, \& Rotheram-Borus, 1994). Specifically, Kipke et al. (1995) found that substance-abusing homeless youth were three and one half times more likely to have been high on drugs or alcohol at last sexual intercourse, twice as likely to have participated in survival sex, and two and one half times more likely to have had a sexually transmitted disease (Kipke et al., 1995). Among high school students, Lowry et al. (1994) found that those who used illicit drugs were more likely to report engaging in sexual intercourse, having four or more sexual partners, and not using a condom at their last sexual encounter compared to students who did not report substance use. The study of runaway youth by Koopman et al. (1994) also found that substance use was associated with number of sexual partners and condom use, which they note as particularly important since these runaways reported very high rates of substance use as well as having friends who frequently used drugs. Similarly, other research has found that alcohol and drug use are the best predictors of sexual risk behavior among inner-city adolescents (Keller et al., 1991). Although high-risk sexual behaviors and substance use have been found to be significantly associated (cf. Kipke et al., 1995), Potterat, Rothenberg, Muth, Darrow, and Phillips-Plummer (1998) point to the importance of the timing and sequencing of these events. In their study of prostitutes, they found that for the majority of these women the use of drugs preceded prostitution. Based on the above studies, we predicted that a positive association would be found between substance use and risky sexual behaviors (See Figure 1, Arrow F).

Research reveals that the majority of runaways report hanging out with friends as their main activity (Yates et al., 1988). Specifically, Kipke, Unger, et al. (1997) note that street peers provide guidance and instruction that aid youth in surviving on the street. Furthermore, it is important for these youth to gain acceptance into peer groups. The results of their study revealed that affiliation with peers strongly influenced the behavior of homeless youth such that those who associated with hustlers were more likely to rely on prostitution to support themselves financially (Kipke, Unger, et al., 1997). Runaway and homeless youth also have been found to have high rates of participation in survival sex and prostitution (Rotheram-Borus et al., 1992). If homeless youth spend the majority of their time with other street youth and are strongly influenced by the behaviors of such youth, it is likely that this will affect the adolescent's decision to engage in similar activi- ties. Studies also have found that runaways who associate with deviant peers are more likely to engage in risky sexual behaviors (Whitbeck et al., 1999). Accordingly, we hypothesized that those who associate with close friends who sold sex would be more likely to engage in high-risk sexual behaviors (See Figure 1, Arrow G).

Homeless youth are at high risk for developing health problems and contracting sexually transmitted diseases (Farrow et al., 1992; Johnson et al., 1996). Many of their health problems are a result of engaging in health-compromising behaviors including unprotected sexual intercourse and survival sex (Farrow et al., 1992; Yates et al., 1988), which often are associated with survival on the streets (Kipke, Unger, et al., 1997; Rotheram-Borus et al., 1992). Studies have found that high rates of both homeless males and homeless females report never or rarely using a condom during intercourse (38\% and 39\%, respectively; Rotheram-Borus et al., 1992). In contrast, among a community sample, the rate of male youth not wearing a condom at last intercourse was 23\% (Sonenstein et al., 1989). High rates of survival sex and having numerous sexual partners in the past month also have been reported among homeless youth (Kipke et al., 1995). Because such behaviors are associated with an increased risk, we predicted that a positive association would be found between risky sexual behaviors and selfreported sexually transmitted diseases (See Figure 1, Arrow H). Finally, the model controlled for the effects of gender.

\section{Method}

Sample

The total sample included 602 adolescents from the Midwest Homeless and Runaway Adolescent Project (MHRAP), a four-state study of runaway adolescents from Missouri, Iowa, Nebraska, and Kansas. Young people were interviewed directly on the streets, in shelters, and in drop-in centers by outreach workers who were trained youth workers with considerable experience interviewing and interacting with this group of young people. They were very familiar with local street cultures and were already known and trusted by many of the runaways. Respondents were recruited as part of the participating agencies' regular intake and outreach programs. Agencies were selected for participation in the study based on their having an existing street outreach program in addition to shelter and/or transitional living facilities. All but one of the study agencies had a street outreach van. This agency had an inner city drop-in center that catered to street youth. There were a total of six agencies: two in St. Louis (Missouri), and one each in Kansas City (Missouri), Wichita (Kansas), Lincoln (Nebraska), and Des Moines (Iowa).

Upon initial contact, the interviewers read the consent statement to the youth and explained the study procedures. Respondents were informed that they could refuse participation, refuse single questions, or stop participating in the interview at any time. They also were informed 
that reports of abuse by adults must be reported by law and that steps would be taken for their protection in the event of disclosure of plans to harm themselves. Adolescents signed the consent form prior to starting the interview. The adolescents were not living under parental supervision at the time of the interview and were considered emancipated. Referral and support services were offered to youths on the street and provided to youths in shelters by the agencies as part of their outreach programs. Agreeing to be interviewed was not a precondition for any of the services the agencies provided. Interviews typically lasted about $11 / 2$ hours. A snack was provided during a break in the interview process, and the adolescent received $\$ 15$ for his or her participation.

Response rates by agency ranged from $71 \%$ to $100 \%$. The average response rate across all agencies was $93 \%$. Of the total 602 adolescents who were interviewed, 241 $(40 \%)$ were male and $361(60 \%)$ were female. The majority of adolescents were either White (61\%) or African American $(24 \%)$ while nearly $3 \%$ were American Indian and $3 \%$ Hispanic. The remaining 9\% were either Asian, biracial, or multiracial. The young people ranged in age from 12 to 22 years with a mean of 16 years. Adolescent males were slightly older on average compared to females, with a mean age of 17 for males and 16 for females. The total amount of time away from home (including time on the street, time in shelters and other institutions, and time with friends and relatives) ranged from 1 day to over 7.5 years, with a median of 61 days. Prior to running away for the first time, 55\% of adolescents were from a metropolitan area or suburb of a metropolitan area of 100,000 people or more. Twenty percent said they lived in cities with a population of 50,000 to 100,000 . The remaining $25 \%$ were from towns of 50,000 people or less.

\section{Measures}

Family abuse was an 11-item scale that asked the adolescent how often a parent or adult caretaker who was supposed to be taking care of them ever threw something at them in anger, pushed them, slapped them, hit them with an object, beat them up with their fists, threatened or assaulted them with a weapon, and/or sexually abused them. The responses on individual items ranged from $0=$ never to $3=$ many times. Due to the fact that there were an unequal number of physical abuse versus sexual abuse items, they were weighted to give equal importance to both sexual and physical abuse indicators in the summed scale. Due to a skewed distribution of the summed scale, the natural logarithm was used in the analysis. The summed scale was coded such that the higher the score, the higher the abuse. Cronbach's $\alpha$ for family abuse was .83 in this sample (physical abuse items adapted from Straus \& Gelles, 1990; sexual abuse items adapted from Whitbeck \& Simons, 1990).

Time on own was the total amount of time the respondent had been on the street or in unsupervised living arrangements (e.g., staying with friends) since first running away from home.
Substance use was measured using 12 items in which adolescents were asked about frequency of use of beer; hard liquor; marijuana; various hard drugs such as cocaine, amphetamines, and heroin; and whether they had ever injected drugs during the past 12 months. The variables were standardized due to different response categories on some of the items and then summed such that the higher the score, the higher the substance use.

Friends selling sex was a dichotomous variable $(0=$ close friends never sold sex, $1=$ close friends sold sexual favors for drugs or money and/or food or shelter).

Risky sexual behaviors was comprised of three dimensions. The first dimension, survival sex, was the sum of three items that asked adolescents if they had ever traded sex for food/shelter, if they had ever traded sex for money/drugs, and if they had ever engaged in prostitution. The second dimension included one item that asked young people how many different sexual partners they had in the past year. The third dimension focused on rates of condom use during vaginal, oral, and/or anal sex. All the variables were coded such that the higher the score, the higher the risky sexual behavior. The three dimensions were standardized due to different response categories and then summed. Cronbach's $\alpha$ for the three dimensions was .56. The somewhat low $\alpha$ reliability was due to the fact that condom use was not highly correlated with the other variables. However, other researchers report similarly low reliabilities when condom use variables are used with other risk behaviors (cf. Ramirez-Valles, Zimmerman, \& Newcomb, 1998; Rotheram-Borus et al., 1992).

Self-reported STDs was an indicator variable in which young people were asked if they had ever had a sexually transmitted disease. The responses were coded 0 (no) and 1 (yes). It is acknowledged that using a single-item, self-reported measure of STDs is problematic because reliability and validity cannot be assessed.

The prevalence of STDs is likely to vary according to the source of data (Cates, 1991). For example, Clark, Brasseux, Richmond, Getson, and D'Angelo (1997) found that only $46 \%$ of adolescents accurately reported STDs. Such inaccuracies have been attributed to difficulties with recall and social desirability biases (Hingson \& Strunin, 1993; Kauth, St. Lawrence, \& Kelly, 1991). Nevertheless, for practical and ethical reasons, self-reports may be the only feasible means of obtaining certain information (Fitzgerald \& Mulford, 1987), especially from homeless persons. Other studies of self-reported STDs among homeless youth (c.f. Johnson et al., 1996) believe that prevalence rates are actually much higher than those reported due to the lack of routine STD tests with this population.

Gender was controlled for in this model and was coded 0 for males and 1 for females.

\section{RESULTS}

The Pearson correlation coefficients, $r$, for the measures used in the present analysis are presented in Table 1 and, due to listwise deletion of missing cases, 569 youth were 
Table 1. Correlation Matrix for Self-Reported Sexually Transmitted Disease Model

\begin{tabular}{|c|c|c|c|c|c|c|c|}
\hline & 1 & 2 & 3 & 4 & 5 & 6 & 7 \\
\hline 2. Gender & $.19 * *$ & -- & & & & & \\
\hline 4. Substance use & $.12 * *$ & $-.13 * *$ & $.17^{* *}$ & -- & & & \\
\hline 5. Friends selling sex & $.20 * *$ & .03 & $.15 * *$ & $.20 * *$ & -- & & \\
\hline behaviors & $.22 * *$ & -.01 & $.23 * *$ & $.47^{* *}$ & $.32 * *$ & -- & \\
\hline 7. Self-reported STDs & $.16^{* *}$ & $.11^{*}$ & .13 ** & $.19 * *$ & $.19 * *$ & $.32 * *$ & -- \\
\hline$M$ & .46 & .60 & 4.06 & .00 & .21 & -.01 & .15 \\
\hline$S D$ & .33 & .49 & 1.82 & 2.25 & .40 & 2.18 & .36 \\
\hline
\end{tabular}

$N=569$.

${ }^{*} p<.05 .{ }^{* *} p<.01$.

included in the present analyses. At the bivariate level, family abuse was significantly associated with all of the remaining variables. Adolescents who experienced higher rates of early family abuse were more likely to be female $(r=.19)$, had spent more time on their own $(r=.20)$, had higher rates of substance use $(r=.12)$, had friends who sold sex $(r=.20)$, had engaged in risky sexual behaviors $(r=.22)$, and reported a sexually transmitted disease $(r$ $=.16)$. Substance use was related to friends selling sex $(r$ $=.20)$, risky sexual behaviors $(r=.47)$, and self-reported STDs $(r=.19)$. Friends selling sex was correlated with risky sexual behaviors $(r=.32)$ and self-reported STDs $(r$ $=.19)$. Finally, risky sexual behavior was positively associated with self-reported STDs $(r=.32)$.

Results of the path analysis are shown in Figure 2 (only significant paths shown). The standardized path coefficients, $\beta$, represent the effect of a given predictor variable on the dependent variable after accounting for the remaining relationships in the model. Because some of the variables were dichotomous, this model was estimated using the weighted least squares procedure in LISREL VIII (Jöreskog \& Sörbom, 1993). Although the $p$-value associ- ated with the chi-square test statistic is small, other goodness-of-fit indices indicate an adequate fit of the model to the data $(\mathrm{GFI}=0.99$, AGFI $=0.97$, and Hoelter's $\mathrm{CN}=402$ : Bollen, 1989; Jöreskog \& Sörbom, 1993).

The model revealed that early family abuse was positively associated with time on own $(\beta=.27)$, indicating that the more abuse, the more time that the adolescent spent on the street or in unsupervised living arrangements. A history of abuse was also positively associated with friends selling sex $(\beta=.19)$ and substance use $(\beta=$ .19). Time on own was positively associated with friends selling sex $(\beta=.11)$, which suggests that the more time adolescents spent on their own, the more likely they were to have associated with deviant peers who sold sex. Time on own was also positively related to risky sexual behaviors $(\beta=.19)$.

Substance use was positively associated with engaging in risky sexual behaviors $(\beta=.41)$. In addition, adolescents who had friends who sold sex were more likely to have engaged in risky sexual behaviors $(\beta=.41)$. Finally, risky sexual behavior was positively associated with selfreported STDs $(\beta=.57)$.

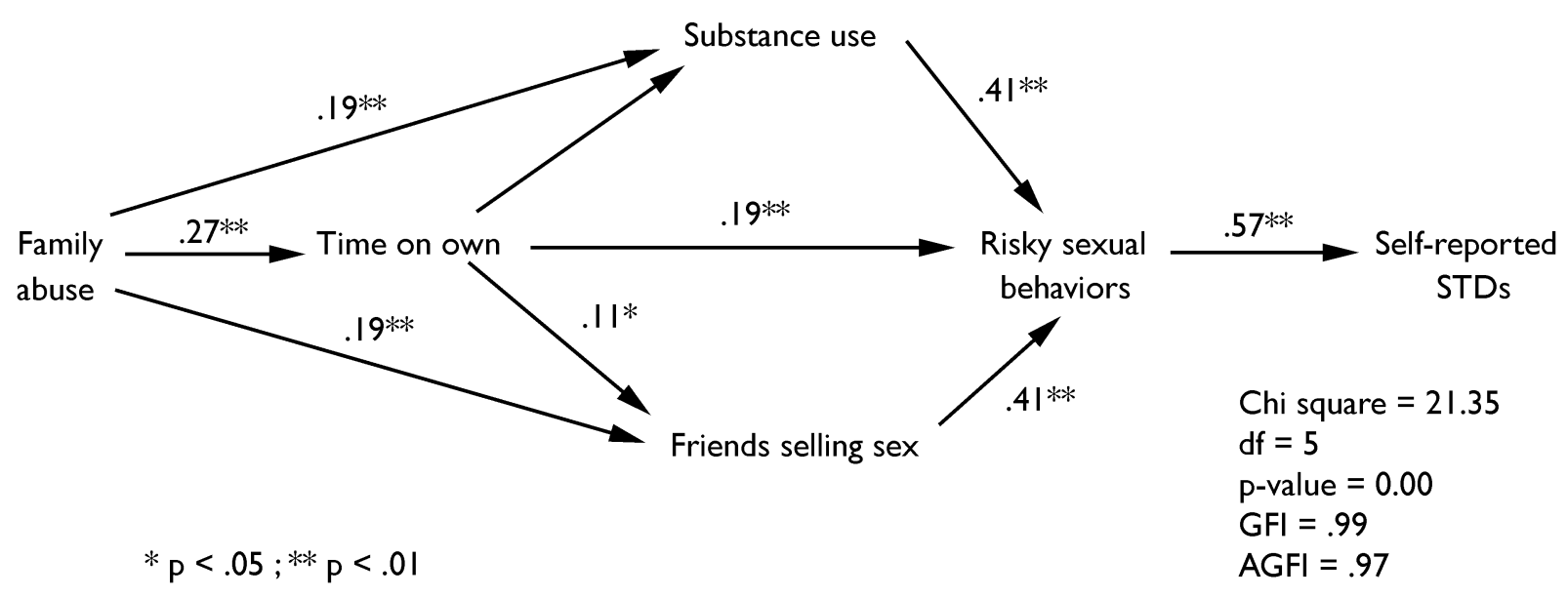

Figure 2. Path model for self-reported STDs among homeless and runaway adolescents (only significant paths shown). 
Males spent more time on their own $(\beta=-.28)$ and reported higher rates of substance use $(\beta=-18)$. In contrast, young women were more likely to have engaged in risky sexual behaviors $(\beta=.25)$ and to have reported having had a sexually transmitted disease $(\beta=.08)$. However, a test for gender interactions revealed that the different paths leading to self-reported STDs did not differ significantly for males and females. The model explained $34 \%$ of the variance in the self-reported STD variable.

The decomposition of the effects of independent variables on the dependent variables (Jöreskog \& Sörbom, 1993) are presented in Table 2. The results indicated that early family abuse had a significant indirect effect on risky sexual behaviors via substance use and friends selling sex. This suggests that many young people who experience high rates of physical and/or sexual abuse are likely to affiliate with deviant peers and report high rates of substance use, which in mm lead to risky sexual behaviors. Family abuse also affected risky sexual behaviors via time on own. Family abuse was also found to indirectly influence self-reported STDs via time on own, friends selling sex, and risky sexual behaviors; through substance use and risky sexual behaviors; and through friends selling sex and risky sexual behaviors.

Time on own had a significant indirect effect on risky sexual behaviors via friends selling sex. Time on own also indirectly influenced self-reported STDs through friends selling sex and risky sexual behaviors. Substance use and friends selling sex both had a significant indirect effect on self-reported STDs via risky sexual behaviors, suggesting that adolescents who associated with deviant peers who sold sex and adolescents who reported high rates of substance use were likely to have engaged in risky sexual be- haviors, which in turn was associated with self-reported sexually transmitted diseases.

\section{DISCUSSION}

This study focused on factors associated with self-reported sexually transmitted diseases among homeless and runaway adolescents. Our results indicated that family abuse was positively related to the amount of time the adolescents spent on their own. It is possible that adolescents reach a certain threshold where they can no longer tolerate the abuse and then run. Spending time on the street or in unsupervised living arrangements may be viewed as an alternative solution to returning home. Coming from an abusive family background was also found to be associated with higher rates of substance use, which is consistent with previous research (Dembo et al., 1989; Garnefski \& Arends, 1998; Harrison et al., 1997). With little support from adult caretakers, the use of alcohol and drugs may serve as a coping mechanism that helps these young people deal with the pain and suffering that many of them experienced as a result of early childhood abuse. Finally, family abuse was related to friends selling sex. Consistent with a risk amplification model (Whitbeck et al., 1999), abusive families provide "basic training" for antisocial behavior that can lead to rejection by conventional peers, thus leading adolescents to form ties with deviant peer groups on the street (Patterson et al., 1984). Affiliating with deviant peers provides support and protection for these youth in the street environment (Hagan \& McCarthy, 1997), especially when they lack conventional family ties (Unger et al., 1998).

Table 2. Decomposition of Effects

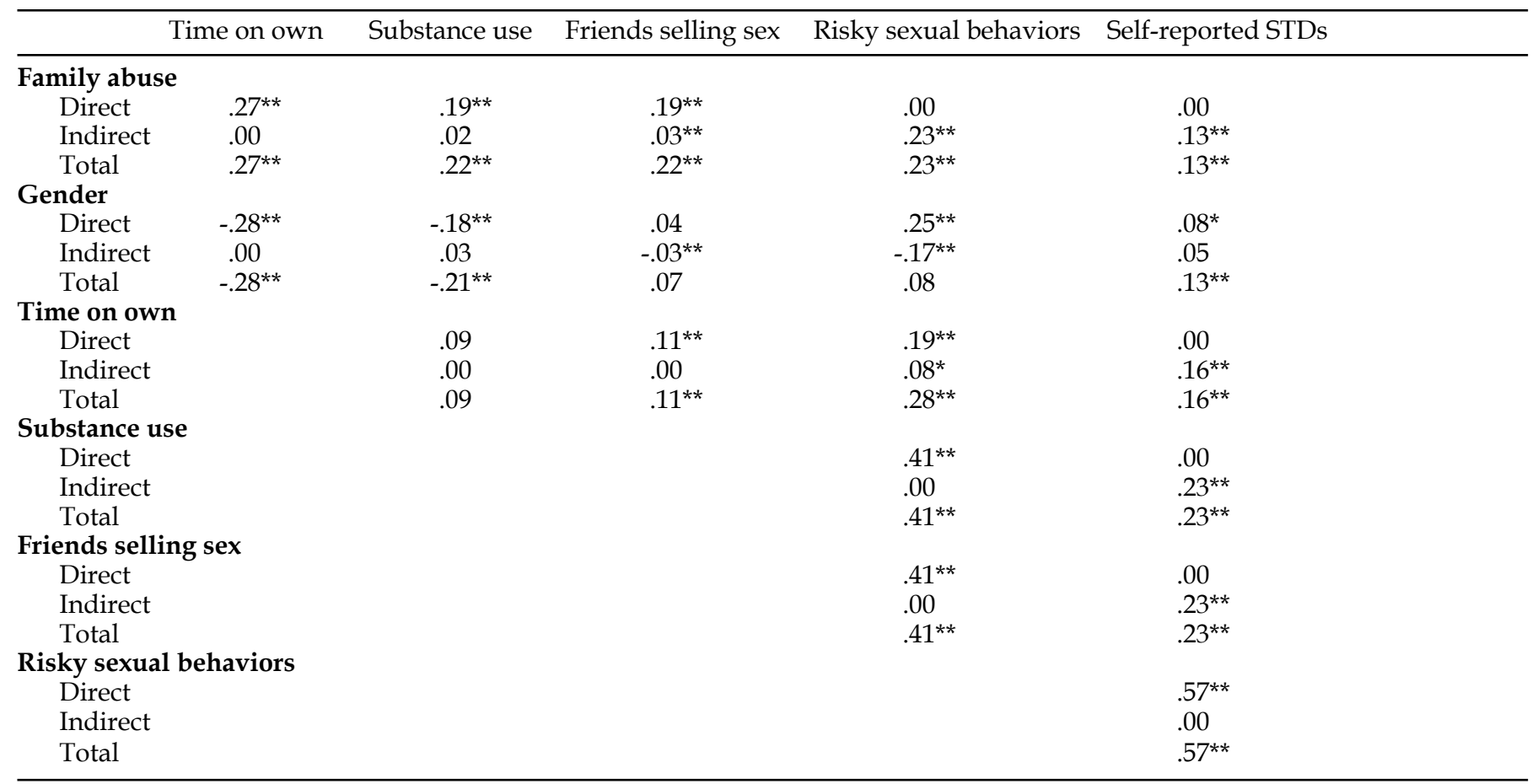

${ }^{*} p<.05 ;{ }^{* *} p<.01$. 
The current findings also revealed that adolescents who spent more time on their own reported associating with deviant peers who sold sex. The more time that youth spend on the street, the more likely they are to be exposed to crime and potential offenders. Therefore, young people are likely to form alliances with other street youth who may provide both protection and support. However, due to the lack of legitimate means of support for these youth, their affiliations are likely to be with deviant peers, who engage in risky, deviant behaviors such as prostitution and survival sex (Hagan \& McCarthy, 1997; Whitbeck \& Hoyt, 1999). Although studies have found that some youth may be able to borrow money from friends and other family members initially (Kipke, Unger, et al., 1997), they will have to rely on other means of support the longer that they are out of their own. Therefore, spending time on their own will lead runaway and homeless youth to form friendships with other street youth, many of who engage in deviant subsistence strategies.

Contrary to what was hypothesized, time on own was not associated with substance use in the current study. It is possible that abused youth were already using alcohol and drugs at home as a coping mechanism; therefore, the amount of time on their own was not a significant factor.

Youth who spent more time on their own were at higher risk for engaging in risky sexual behaviors. The street culture provides adolescents with few means of support; therefore, many are forced to trade sex for food, money, and/or a place to stay (Silbert \& Pines, 1981; Weisberg, 1985). Furthermore, obtaining condoms may not be a priority for many youth, especially when they are concerned about how they are going to pay for their next meal and find a safe place to sleep for the night. In addition, street youth have few resources available; therefore, some of them may not have access to condoms. This finding is consistent with prior research, which suggests that street youth use condoms inconsistently (Anderson et al., 1994; Rotheram-Borus et al., 1992). Finally, youth who are exposed to the street environment for longer time periods (especially those who are trading sex) are at greater risk for having multiple sex partners.

The current study also found that substance use was related to risky sexual behaviors. Consistent with previous research (Kipke et al., 1995; Koopman et al., 1994; Lowry et al., 1994), young people who report high alcohol and/or drug use are more likely to engage in survival sex, have numerous sexual partners, and use condoms inconsistently during sexual intercourse. It is possible that being intoxicated or high lowers peoples' inhibitions, which may result in them having sex with numerous partners. In addition, some adolescents may get drunk prior to engaging in prostitution because it makes it somewhat easier to deal with the casualness of their encounters (Weisberg, 1985). Finally, the likelihood of street youth using condoms during sexual intercourse is likely to be reduced when they have been using alcohol and/or drags (Koopman et al., 1994).

Having close friends who sold sex was related to the youth engaging in risky sexual behaviors. Since young people spend most of their time hanging out with other street youth (Yates et al., 1988) and are influenced by the behaviors of such youth (Kipke, Unger, et al., 1997), it is likely that their peers have a very strong influence in their lives, which may lead them to engage in similar activities. Therefore, if their close friends are trading sex, youths are likely to engage in similar behaviors. Youths soon realize that there are few legitimate means of survival on the street and if their peers, whom they look to for support and protection, are engaging in prostitution and/or trading sex, it is likely that the youth will see this as a legitimate means of support. This finding is supported by previous research whereby youth who associate with hustlers are also likely to rely on prostitution and survival sex as a way to support themselves financially (Kipke, Unger, et al., 1997). Supporting oneself through prostitution and survival sex is also likely to be associated with numerous sexual partners.

Youths who traded sex, had multiple sex partners, and did not practice safe sex (i.e., risky sexual behaviors) were more likely to report having had a sexually transmitted disease. Lacking conventional ties, street youth have few legitimate means of support and when they are hungry and need money, trading sex and prostitution may be a last resort (Silbert \& Pines, 1981). Previous research reveals that homeless youth have high rates of survival sex, numerous sexual partners (Kipke et al., 1995), and inconsistent condom use (Rotheram-Borus et al., 1992).

As such, those who engage in risky sexual behaviors are likely to be at risk for many health problems, including sexually transmitted diseases. Moreover, although females were more likely to have reported having had an STD, we failed to find gender differences in the pathways that lead to self-reported STDs.

Consistent with previous research (Lowry et al., 1994; Yates et al., 1988), the current study finds a positive association between engaging in high-risk behaviors and selfreported sexually transmitted diseases. However, this study also takes into account the amount of time at risk and early family history as precursors to young people's involvement in high-risk behaviors. This early life history approach accounts for why these young people are out on the street in the first place. The results of this study support our interpretations from a risk amplification perspective (Whitbeck et al., 1999). Early life abusive experiences set in motion a sequence of events that, among other outcomes, are associated with self-reported sexually transmitted diseases.

There are some limitations that should be noted in the present study. The first is the reliance on cross-sectional data. Although longitudinal data are needed to establish causation, the use of a life-course perspective that takes into account early life histories seems promising. In addition, the intervening street experiences variables, which are time-delimited variables that help strengthen the causal argument, have significant effects for young people's risk for self-reported sexually transmitted diseases. Another limitation is participants' self-reports. However, 
respondents were informed that their responses would be confidential, and the interviewers were very familiar with local street cultures and were already known and trusted by many of the runaways. For these reasons, it is less likely that the participants would be motivated to bias their responses. Moreover, comparisons done on runaway adolescents and their parents reveals that these young people do not appear to be overreporting family abuse (Whitbeck, Hoyt, \& Ackley, 1997b). Another limitation is that some of the measures were retrospective in nature, which may have resulted in some over- or underreporting. Finally, our outcome measure is a single self-report question. As such, it focuses on perceptions of STDs. Therefore, it is not possible to evaluate the reliability and validity of this measure. It is possible, for example, that some adolescents have an STD without knowing it or may be reporting an STD when they do not have one. This may lead to some youth over- or underreporting histories of STDs (cf. Clark et al., 1997).

Street youth in this study are at risk for contracting sexually transmitted diseases. Although early intervention may not remediate the effects of early abuse for these street youth, such programs may prevent the possibility of the amplification of such effects, thereby reducing young people's participation in deviant, risky behaviors and, ultimately, lowering the risk of contracting STDs.

In summary, adolescents who experience high rates of abuse within the home find themselves spending more time on the street or in unsupervised living arrangements. These young people often form ties with other street youth and report high rates of alcohol and drugs, which leads to their involvement in high-risk sexual behaviors such as survival sex and prostitution. Participation in such activities is likely to put adolescents at risk for a variety of serious health problems including sexually transmitted diseases.

\section{References}

Anderson, J. E., Freese, T. E., \& Pennbridge, J. N. (1994). Sexual risk behavior and condom use among street youth in Hollywood. Family Planning Perspectives, 26, 22-25.

Bollen, K. A. (1989). Structural equations with latent variables. New York: John Wiley \& Sons.

Cates, Jr., W. (1991). Teenagers and sexual risk taking: The best of times and the worst of times. Journal of Adolescent Health, 12, 84-94.

Cauce, A. M., Paradise, M., Embry, L., Morgan, C. J., Lohr, Y., Theofelis, J., Heger, J., \& Wagner, V. (1998). Homeless youth in Seattle: Youth characteristics, mental health needs, and intensive case management. In K. Kutash, A. Duchnowski, \& M. Epstein (Eds.), Community-based programming for children with serious emotional disturbances: Research and evaluation (pp. 611-632). Baltimore: Brookes Publishing.

Clark, L. R., Brasseux, C., Richmond, D., Getson, P., \& D'Angelo, L. J. (1997). Are adolescents accurate in self-reports of frequencies of sexually transmitted diseases and pregnancies? Journal of Adolescent Health, 21, 91-96.

Dembo, R., Williams, L., LaVoie, L., Berry, E., Getreu, A., Wish, E. D., Schmeidler, J., \& Washburn, M. (1989). Physical abuse, sexual victimization, and illicit drug use: Replication of a structural analysis among a new sample of high-risk youths. Violence and Victims, 4, 121-138.

Elder, G. (1997). Life course and human development. In R. Lerner (Ed.), Handbook of child psychology: Vol. 1. Theoretical models of human development (pp. 939-991). New York: Wiley.

Farrow, J. A., Deisher, R. W., Brown, R., Kulig, J. W., \& Kipke, M. D. (1992). Health and health needs of homeless and runaway youth. Journal of Adolescent Health, 13, 717-726.

Fitzgerald, J. L., \& Mulford, H. A. (1987). Self-report validity issues. Journal of Studies on Alcohol, 48, 207-210.

Fortenberry, J. D., Costa, F. M., Jessor, R., \& Donovan, J. E. (1997). Contraceptive behavior and adolescent lifestyles: A structural modeling approach. Journal of Research on Adolescence, 7, 307-329.

Garnefski, N., \& Arends, E. (1998). Sexual abuse and adolescent maladjustment: Differences between male and female victims. Journal of Adolescence, 21, 99-107.

Hagan, J., \& McCarthy B. (1997). Mean streets: Youth crime and homelessness. New York: Cambridge University Press.

Harrison, P. A., Fulkerson, J. A., \& Beebe, T J. (1997). Multiple substance use among adolescent physical and sexual abuse victims. Child Abuse \& Neglect, 21, 529-539.

Hingson, R., \& Strunin, L. (1993). Commentary: Validity, reliability, and generalizability in studies of AIDS knowledge, attitudes, and behavioral risks based on subject self-report. American Journal of Preventive Medicine, 9, 62-64.

Janus, M., McCormack, A., Burgess, A. W., \& Hartman, C. (1987). Adolescent runaways: Causes and consequences. Lexington, MA: Lexington Books.

Johnson, T. P., Aschkenasy, J. R., Herbers, M. R., \& Gillenwater, S. A. (1996). Self-reported risk factors for AIDS among homeless youth. AIDS Education and Prevention, 8, 308-322.

Jöreskog, K., \& Sörbom, D. (1993). LISREL 8: User's reference guide. Chicago: Scientific Software.

Kauth, M. R., St. Lawrence, J. S., \& Kelly, J. A. (1991). Reliability of retrospective assessments of sexual HIV risk behavior: A comparison of biweekly, three-month, and twelvemonth self-reports. AIDS Education and Prevention, 3, 207-214.

Keller, S. E., Bartlett, J. A., Schleifer, S. J., Johnson, R. L., Pinner, E., \& Delaney, B. (1991). HIV-relevant sexual behavior among a healthy inner-city heterosexual adolescent population in an endemic area of HIV. Journal of Adolescent Health, 12, 44-48.

Kipke, M. D., Montgomery, S. B., Simon, T. R., \& Iverson, E. F. (1997). Substance abuse disorders among runaway and homeless youth. Substance Use \& Misuse, 37, 969-986.

Kipke, M. D., O'Connor, S., Palmer, R., \& MacKenzie, R. G. (1995). Street youth in Los Angeles: Profile of a group at high risk for human immunodeficiency virus infection. Archives of Pediatrics \& Adolescent Medicine, 149, 513-519. 
Kipke, M. D., Unger, J. B., O'Connor, S., Palmer, R. F., \& LaFrance, S. R. (1997). Street youth, their peer group affiliation and differences according to residential status, subsistence patterns, and use of services. Adolescence, 32, 655-669.

Koopman, C., Rosario, M., \& Rotheram-Borus, M. J. (1994). Alcohol and drug use and sexual behaviors placing runaways at risk for HIV infection. Addictive Behaviors, 19, 95-103.

Lowry, R., Holtzman, D., Truman, B. I., Kann, L., Collins, J. L., \& Kolbe, L. J. (1994). Substance use and HIV-related sexual behaviors among US high school students: Are they related? American Journal of Public Health, 84, 1116-1120.

Page, C. (1995). Adolescents, HIV/AIDS and other sexually transmitted diseases (STDs). Advocates for Youth, January, 2-3.

Patterson, G. R. (1982). Coercive family processes. Eugene, OR: Castilia.

Patterson, G. R., DeBaryshe, B. D., \& Ramsey, E. (1989). A developmental perspective on antisocial behavior. American Psychologist, 44, 329-335.

Patterson, G. R., Dishion, T J., \& Bank, L. (1984). Family interaction: A process model of deviancy training. Aggressive Behavior, 10, 253-267.

Potterat, J. J., Rothenberg, R. B., Muth, S. Q., Darrow, W. W., \& Phillips-Plummer, L. (1998). Pathways to prostitution: The chronology of sexual and drug abuse milestones. The Journal of Sex Research, 35, 333-340.

Ramirez-Valles, J., Zimmerman, M. A., \& Newcomb, M. D. (1998). Sexual risk behavior among youth: Modeling the influence of prosocial activities and socioeconomic factors. Journal of Health and Social Behavior, 39, 237-253.

Rotheram-Borus, M. J., Meyer-Bahlburg, H. F. L., Koopman, C., Rosario, M., Exner, T M., Henderson, R., Matthieu, M., \& Green, R. S. (1992). Lifetime sexual behaviors among runaway males and females. The Journal of Sex Research, $29,15-29$.
Silbert, M. H., \& Pines, A. M. (1981). Sexual child abuse as an antecedent to prostitution. Child Abuse \& Neglect, 5, 407-411.

Sonenstein, F. L., Pleck, J. H., \& Ku, L. C. (1989). Sexual activity, condom use and AIDS awareness among adolescent males. Family Planning Perspectives, 21, 152-158.

Straus, M., \& Gelles, R. (1990). Physical violence in American families. Brunswick, NJ: Transaction Books.

Unger, J. B., Kipke, M. D., Simon, T. R., Johnson, C. J., Montgomery, S. B., \& Iverson, E. (1998). Stress, coping, and social support among homeless youth. Journal of Adolescent Research, 13, 134-157.

Weisberg, D. K. (1985). Children of the night: A study of adolescent prostitution. Lexington, MA: Lexington Books.

Whitbeck, L. B., \& Hoyt, D. R. (1999). Nowhere to grow: Homeless and run-away adolescents and their families. New York: Aldine De Gruyter.

Whitbeck, L. B., Hoyt, D. R., \& Ackley, K. A. (1997a). Abusive family backgrounds and later victimization among runaway and homeless adolescents. Journal of Research on Adolescence, 7, 375-392.

Whitbeck, L. B., Hoyt, D. R., \& Ackley, K. A. (1997b). Families of home less and runaway adolescents: A comparison of parent/caretaker and adolescent perspectives on parenting, family violence, and adolescent conduct. Child Abuse \& Neglect, 21, 517-528.

Whitbeck, L. B., Hoyt, D. R., \& Yoder, K. A. (1999). A risk-amplification model of victimization and depressive symptoms among runaway and homeless adolescents. American Journal of Community Psychology, 27, 273-296.

Whitbeck, L. B., \& Simons, R. L. (1990). Life on the streets: The victimization of runaway and homeless adolescents. Youth \& Society, 22, 108-125.

Yates, G. L., MacKenzie, R., Pennbridge, J., \& Cohen, E. (1988). A risk profile comparison of runaway and non-runaway youth. American Journal of Public Health, 78, 820-821. 